\title{
Retraction
}

\section{Retraction: Acidotoxicity and acid-sensing ion channels contribute to motoneuron degeneration}

\author{
ÁT Behan, B Breen, M Hogg, I Woods, K Coughlan, M Mitchem and JHM Prehn \\ Cell Death and Differentiation (2014) 21, 344; doi:10.1038/cdd.2013.162; published online 1 November 2013
}

Retraction to: Cell Death and Differentiation (2013) 20, 589-598; doi:10.1038/cdd.2012.158

The authors wish to retract the above paper. The journal has recently been notified by a reader who expressed concerns about some of the figures in this paper. Dr. Áine Behan, coinvestigator of this study, has acknowledged sole responsibility for errors affecting certain panels in Figures $2 b$ and 5 , in which data were processed with the result that the figure panels do not correctly reflect the original data. Dr. Behan and co-author Dr. Bridget Breen have acknowledged responsibility for clerical errors in Figures 8b and 2a, respectively. Dr. Behan and Dr. Breen regret these errors, of which the co-authors Marion Hogg, Ina Woods, Karen Coughlan, Mollie Mitchem and Jochen Prehn were completely unaware. We thank the reader for bringing this to our attention and sincerely apologize to the scientific community for any confusion or adverse consequences resulting from the publication of these data. 